\title{
Blanchot y la imposibilidad de la literatura como experiencia
}

Carlos Surghi

CONICET- Universidad Nacional de Córdoba- Argentina

\begin{abstract}
Resumo
Este artigo analisa a forma como o ensaísta francês Maurice Blanchot argumenta que toda a literatura do século XX tornou-se uma experiência impossível. Analisamos a noção de trabalho presente no livro $O$ Espaço Literário (1959), onde Blanchot constrói uma noção de literatura que pode ser entendida como um processo e não como um objeto, ou seja, uma noção que leva em conta os aspectos de composição antes que a obra literária formal. Assim, o nosso papel é analisar a leitura que Blanchot faz do conceito de autonomia do trabalho escrito como arte, especialmente na análise da relaçáo entre a escrita e experiência em Franz Kafka, escrita de leitura, onde Blanchot percebe uma necessidade para a escrita e experiência de sua impossibilidade.
\end{abstract}

Palavras-chave: experiência; trabalho; autonomia; gravação; impossibilidade.

\begin{abstract}
This paper analyzes how the French essayist Maurice Blanchot argues that throughout the twentieth century literature has become an impossible experience. We analyzed the notion of work present in The space of Literature (1959), where Blanchot constructs a notion of literature that can be understood as a process rather than as an object, ie, a notion that takes into account the compositional aspects before formal literary work. Thus our paper is to analyze the reading and writing that Blanchot makes the concept of work as autonomy of art writing, particularly in the analysis of the relationship between writing and experience in Franz Kafka, where Blanchot perceives a need for writing and experience of its impossibility.
\end{abstract}

Keywords: experience; work; autonomy; writing; impossibility. 
1. DANTO, Arthur. Después del fin del arte, 1999, p. 20.

2. Dicho alcance está explicitado por Jacques Rancière en su libro La palabra muda. Ensayo sobre las contradicciones de la literatura, donde se expone que "ni la idea imprecisa del repertorio de las obras de la escritura, ni la idea de una esencia particular capaz de conferir a esas obras su calidad 'literaria" alcanza para que la crítica se aventure en una distinción literaria que, como tal y específica a su objeto, ya ha sido borrada. RANCIÈRE, Jacques. La palabra muda. Ensayos sobre las contradicciones de la literatura, 2009, p. 15.

3. BLANCHOT, Maurice. "Los grandes reductores", 2002a, p. 77. Cabe señalar que un arte más allá de lo humano es un arte que como tal se piensa por fuera del pensamiento o en el fin mismo del arte; es decir en aquello que ya, o desde siempre, no posee representación pues pasa a ser pura voz, puro cuerpo antes que idea o concepto en el sentido estricto de la representación. Respecto a esto ver AGAMBEN, Giorgio. El lenguaje y la muerte. Un seminario sobre el lugar de la negatividad, 2008 e Infancia e historia. Destrucción de la experiencia y origen de la historia, 2004.

4. Ibídem, p. 81.

\section{El grado cero de la experiencia}

De todas las expresiones artísticas que a lo largo del siglo XX evidenciaron los alcances de la modernidad sobre la condición humana, la literatura ha sido sin lugar a dudas la práctica en donde los niveles de experimentación se han dado con mayor intensidad; donde, como plantea Arthur Danto, hablar "después del fin del arte" tal vez no sea otra cosa más que hablar del fin del sujeto en el sentido de que su nivel de expresión denota una manifiesta oscuridad. Es más, podríamos decir que todo procedimiento discursivo en el terreno literario se ha disuelto como tal, ha perdido su carácter representativo y mimético en procura de lograr un nuevo alcance ${ }^{2}$. Por lo tanto en determinados momentos ese nuevo alcance es una experiencia que está por afuera de lo literario, en una zona allende lo posible de representar, en el exterminio de toda condición y forma, en la imposible reiteración de cualquier experiencia.

Sin embargo esa representación de lo nuevo tiene que ver con el origen mismo de una literatura que ya no puede escribirse según los parámetros tradicionales de preceptivas o procedimientos creativos consagrados. Por sólo citar un ejemplo podríamos decir que la ejecución de cualquier obra parecería demandar hasta las últimas fuerzas del sujeto que la llevaba adelante; y tal vez por eso mismo se ha vuelto habitual hablar de la maldición o el padecimiento de la escritura, de una práctica de la literatura que se cobra la vida de quien la ejecuta y que finalmente se consagra en esa especie de aniquilación premeditada que es todo libro que termina con su autor. Tal es el caso de Kafka por ejemplo, quien pide destruir sus manuscritos inconclusos pues la muerte le pone fin a su obra y no su propia voluntad compositiva, la cual por otro lado era extremadamente autoexigente. Pero efectivamente un arte que está más allá de lo humano es un arte sin sujeto, un arte que se realiza por fuera de lo que Blanchot llama los grandes reductores: el estado, la lengua y la metafísica ${ }^{3}$. Ahora bien un arte por fuera de la reducción no es otra cosa que una arte venidero, próximo a una nueva forma y a una experiencia aun no provista de palabras, pues como señala el mismo Blanchot:

ciertamente las obras, ya se trate de libros o de otras formas artísticas, son productos, pero lo que se produce no son solamente riquezas en el sentido más general, sino opiniones, después valores, más tarde formas y el oscuro poder de dar o negar el sentido, la palabra venidera. ${ }^{4}$

De este modo en más de un sentido la tan mentada muerte del autor no refiere solamente a la preponderancia discursiva en 
la representación del mundo, sino también al padecimiento de tener que hablar por medio del lenguaje, y a la vez, de ser el lenguaje mismo quien expresa esa muerte. El escritor argentino César Aira, distante de esa experiencia en sus novelas y haciendo una especie de elogio del procedimiento por sobre los resultados, ha expuesto un poco esa paradoja de obras verdaderamente monstruosas no solo por su extensión sino por la experiencia que significaron para quienes las hicieron. Aira señala que "mientras Balzac escribió cincuenta novelas, y le sobró tiempo para vivir, Flaubert escribió cinco, desgarrándose, Joyce escribió

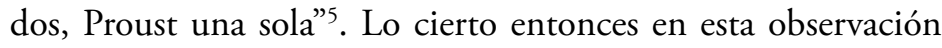
decreciente es que desde finales del siglo XIX y comienzos del siglo XX la literatura podría considerarse como una experiencia de riesgo, como "un trabajo que invadió la vida, la absorbió, como un hiperprofesionalismo inhumano" ${ }^{6}$.

Es así que la condición inhumana del arte es lo que ha vuelto imposible una experiencia del arte, de la literatura misma. Ahí entonces donde espera la última novela de veinte años de elaboración y siete gruesos volúmenes que acaban sustrayendo del mundo a su autor, encerrándolo en su habitación y acelerando su muerte, parecería estar hablando la forma última de una práctica que ya no tiene mucho que ver con los resultados o los objetos que la representan, sino más bien con una especie de insatisfacción siempre distante y llena de ansiedades. En cierto sentido, la obra como objeto formal acabado importa menos que el proceso entendido como padecimiento, pues en ese procedimiento encontramos lo que podríamos llamar la práctica de la literatura como experiencia imposible.

Sin embargo esa experiencia de una literatura que al realizarse no sólo disuelve las formas que la preceden sino también la subjetividad que la lleva adelante, tiene que ver con que la literatura misma se ha vuelto una experiencia imposible. Imposible en el sentido de llevarla a acabo como obra, e imposible en el sentido de reducirla a una imagen que nos ayude a pensarla como un objeto de límites precisos. De este modo, la literatura es también el espacio en el cual el pensamiento moderno se reconoce frente a la desgracia de un mundo que, al ser representado, escapa una y otra vez a los esfuerzos del lenguaje, el escritor y la obra. Al respecto, en su libro Maurice Blanchot. El ejercicio de la paciencia, Sergio Cueto sostiene que la imposibilidad de la literatura es en verdad su respuesta ante la presencia de la desgracia. Tanto es así que volverse imposible es una imposición del instante en el cual la literatura puede acontecer, puede ser necesaria para hablar de lo que ya no se puede hablar o de aquello que no soporta palabra alguna. Sin embargo, la desgracia viene a ser el límite mismo del pensamiento, el pensar sobrellevado por la catástrofe o el pensamiento producto del hundimiento que hace que la literatura surja cuando todo parece desaparecer;
5. AIRA, César. "La nueva escritura”. Revista Boletín, 2002, p. 165.

6. Ibídem, p. 165. 
7. CUETO, Sergio. Maurice Blanchot. El ejercicio de la paciencia, 1997, p. 7. Respecto a las posibilidades de la literatura y su relación con el pensamiento contemporáneo ver: BIDENT, Christophe. Maurice Blanchot, partenaire invisible, 1998; SCHULTE NORHOLT, AnneLise. Maurice Blanchot. L'écriture como expérience du dehors, 1995; y, HILL, Leslie. Blanchot: Extreme Contemporary, 1997. Así mismo recomendamos: ARRANZ, Manuel. "Blanchot, la literatura y la muerte", 2003.

8. En líneas generales los estudios sobre Blanchot rescatan estas características centrales de su pensamiento, tal como el clásico estudio de COLLIN, Françoise. Maurice Blanchot et la question de l'écriture, 1971; y los recientes aportes de AYACHE, Élie. L'écriture Postérieure, 2006 y LIMET, Yun Sun. Maurice Blanchot critique, 2010.

9. Al respecto, para la idea de experiencia límite señalamos el texto de DEL BARCO, Oscar. "Leer a Blanchot", 2008.

10. Para un abordaje de la relación singular de distancia y proximidad, cuando no conflictiva, de Maurice Blanchot con la filosofía, señalamos el número especial que le dedicara la Revista Anthropos: Huellas del conocimiento, en particular: SAMANIEGO, Alberto Ruiz.

"Maurice Blanchot: una estética de lo neutro", 2001. Así como: MICHAUD, Ginette. Tenir au secret (Derrida, Blanchot), 2006 y ZARADER, Marlène. L'être et le neutre. À partir de Maurice Blanchot, 2000. cuando cualquier tipo de experiencia resulta justamente imposible. Al respecto, Cueto señala lo siguiente: "Pensar la desgracia es velar la desaparición incesante que no tendrá lugar, convertir al pensamiento en el lugar de la desaparición de la desgracia, la inapariencia de la literatura"”.

De este modo, la literatura como experiencia de riesgo o como experiencia de la desgracia es una forma de pensar la negatividad misma de la experiencia, la evidencia de que en el mundo contemporáneo ésta falta a los sujetos aún cuando, como tal, sólo puede ser negativa. Pero en definitiva, ¿a qué se debe esta especie de extremismo formal de la literatura para hablar de un mundo imposible?, ¿a qué responde su deseo de desaparecer tras lo inhumano?, ¿por qué su reticencia es la primera y la última evidencia de que como forma desaparece tras la experiencia? Sin lugar a dudas el pensamiento de Maurice Blanchot gira alrededor de estas palabras, se mantiene próximo y distante a ellas en un ejercicio de definición e impugnación que busca hablar de aquello que está afuera del discurso. Sin embargo, Blanchot nos ha entregado una última palabra sobre los límites de la literatura y esa palabra está en el análisis que le dedica a la obra literaria como experiencia de algo que ya se ha vuelto imposible.

\section{Escribir la experiencia de la obra}

Para Blanchot, la literatura es una experiencia que se relaciona con la ejecución de la obra. Escribir es sustraerse al tiempo, asumir una impersonalidad y una neutralidad respecto a la reducción del mundo que se lleva adelante con una metafísica de oposiciones. Ahora bien, antes que un objeto, un artefacto o un elemento discursivo, la obra es el resultado de un proceso al cual el artista o el escritor se consagran ${ }^{8}$. Lo singular entonces es que agotada la experiencia del mundo, transformado el arte en una experiencia de silencio y parálisis; el acto de escritura, el empleo de lo imaginario o la fascinación del lenguaje pasan a ocupar el lugar que le correspondería a la experiencia. Pero ocupan ese lugar privados de su condición de expresión transparente que, como señalan Benjamin y Agamben, con el devenir de la historia ha ido desaparecido. La obra entonces se vuelve un misterio, una experiencia que en su ejecución se revela a quien la padece y la experimenta; la obra en sí es una experiencia del límite de las palabras ${ }^{9}$. Pero la obra al mismo tiempo, la obra es una experiencia de la ausencia de la verdad, de la seguridad de la filosofía y el pensamiento ${ }^{10}$.

Teniendo en cuenta lo anteriormente expuesto, habría que señalar que la obra literaria que interesa a Blanchot no es la que 
cumple con su realización formal, con su fidelidad en cuanto a la adecuación entre la percepción de un sujeto y el estado de verdad del mundo; sino todo lo contrario, la obra que interesa a Blanchot es aquella que cumple con la representación de lo intenso que supone su realización, y que en dicha realización sobrepasa a la inteligencia que pone en funcionamiento un saber hacer, una TÉxun que evidencia lo inhumano del sujeto que la ejecuta. Así, en la obra no hay ni un antes ni un después, sino una frecuencia, una duración o intensidad, que justamente en su expresión de lo imaginario como poder de representación, o como negación de la misma representación, embiste contra una serie de valores que serían los orígenes de la obra entrevista o pergeñada como objeto en el mundo dispuesto y pensado para perdurar, ya sea como testimonio o como obra de arte que se perpetúa en el tiempo.

Pero, ¿qué ocurre entonces cuando se superpone a la obra un imperativo trascendente como la finalidad, la utilidad, la transparencia misma del arte que, como tal, se han perdido al dejar de ser mera representación? ¿Qué ocurre cuando la obra es necesidad e imposición de un constante estado de riesgo, como lo son las experiencias de Kafka, Rilke o Mallarmé, en función de aquello para lo cual no hay palabras? ¿Qué ocurre cuando la obra es contemplación, posibilidad de salvación o contacto con lo sagrado antes que su propia realización como forma autónoma? En definitiva, ¿por qué la obra termina por realizar una experiencia que se corresponde con la intimidad del sujeto, como lo es por caso la escritura, cuando en verdad este mismo sujeto carece de experiencia alguna? ${ }^{11}$ Blanchot sabe que cada una de estas preguntas responde al caso del escritor que, por ejemplo, cree justificar su soledad en la obtención de una respuesta, en la apuesta por una salvación que depende siempre de su fuerza y de su convencimiento respecto a las posibilidades que depara lo escrito. Pero aún así, cualquier respuesta sería tentativa, insuficiente y escéptica de su propia adecuación a aquello que hay de irreductible en cualquier experiencia.

Podríamos decir entonces que la obra literaria una vez emprendida adopta una forma circular que en sí no conduce a ninguna parte; sino que, todo lo contrario, bajo esa forma se sustrae a todo lo circundante llegando a ser un espacio al margen de la intimidad donde se produce. Parecería ser como si en la obra Blanchot situara esa poderosa "necesidad interior de escribir", porque en realidad en el centro de ese círculo el escritor "se expone peligrosamente a la presión que le exige que escriba" aunque "así también se protege"12 del desencanto del mundo contra el cual su voluntad se revela. Nada más arduo entonces para un escritor privado de experiencias en el mundo -y que siente la cercanía de ese espacio literario- que sus relaciones previas en el mundo como pueden ser el orden del tiempo, las obligaciones de
11. En cuanto a la relación experiencia-intimidad en el pensamiento contemporáneo ver BÜRGER, Christa; BÜRGER, Peter. La desaparición del sujeto. Una historia de la subjetividad de Montaigne a Blanchot, 2001.

12. BLANCHOT, Maurice. El espacio literario, 1969, p. 45. 
13. Ibídem, p. 46.

14. Ibídem, p. 47.

15. Ibídem, p. 48.

16. Ibídem, p. 49. la vida en comunidad, el trabajo utilitario, la seriedad de la vida; todo aquello que de algún modo lo encadena a permanecer demasiado anclado en la existencia, y que, por cierto, ahora se verá rotundamente modificado al entrar en contacto con la fuerza de ese espacio inmanente que es la obra, su única experiencia.

Por momentos, entonces, la obra es una experiencia que borra la continuidad del mundo. Sustraída a toda forma de encuadre -entiéndase horarios, cumplimientos, autodemandas de una figura de escritor- la escritura supone para quien la ejecuta un desplazamiento constante de todo límite. En definitiva, lo literario experimentado como una demanda sin reclamo -es decir como autonomía del arte, pero también como algo más que mera autonomía- no es más que la imposibilidad de todo mundo anterior a la escritura, de todo mundo sin palabras, de todo espacio anterior al literario que sólo puede pensarse como tal en la presencia misma de lo literario. Pero por otro lado, la obra también es la única experiencia posible en este mundo, pues ella ha roto cualquier tipo de referencialidad entre el lenguaje y lo real.

En medio de esta dicotomía Blanchot señala que para el escritor lo que define "los riesgos de su experiencia" es ese sentimiento de estar "privado del mundo", "ausente de sî"13. Ahora bien, ese sentimiento de pérdida surge como experiencia cuando quien escribe "no es él mismo"14. De este modo, Blanchot no hace más que describirnos el carácter complejo del artista adentro del espacio literario, allí donde "el lenguaje es sin sentido" y tal vez más oscuro que en cualquier profecía a develar. Pero al adjudicarle el dominio de lo que él considera "el afuera de la palabra" o "la palabra errante"15 con la cual el escritor deberá elevar la obra por sobre el mundo y por sobre él mismo, lo que hace es disminuirlo en tanto que ser, resaltando aún más su condición de sujeto débil ante la necesidad de la obra que lo lleva a experimentar el rechazo, el exilio, la puesta a prueba de sí ante el devenir, y por sobre todo, la imposición de la liberación como triunfo o fuga del mundo que se negaba.

La obra, entonces, para el artista anula la necesidad del mundo, pero al mismo tiempo devuelve una versión de éste totalmente irremplazable, única y original, podríamos decir si aceptamos que cada experiencia es el revés de cada sujeto. Parecería entonces como si la ley secreta del círculo de la obra tuviese una serie de pasos a seguir. Primero apega al escritor a su elaboración, es decir lo separa de cualquier otra actividad y le otorga su hacer, como por caso Mallarmé y la musa de la destrucción; luego lo separa en el momento de su cumplimiento, lo vuelve un ser extraño frente a su criatura. Y, finalmente, lo rechaza y lo sitúa en un instante de inmovilidad fría y oscura que le demanda nada más ni nada menos que la desmesura de llevar adelante la comprensión de "una separación incomprensible"16 al entrar en 
funcionamiento los mecanismos de la ley de inmanencia de la obra; es decir, lo deja presa de lo irrepetible o la renuncia frente a lo que ya no puede ser reiterado. Por lo tanto, la experiencia de la obra consiste en ese retiro del mundo a través del arte, pero al mismo tiempo en esa imposibilidad de vivir en la intemperie de lo imaginario. Blanchot parece decirnos que quien se entrega a la experiencia de la obra por lo general no está en condiciones de volver al mundo, pero tampoco puede permanecer en el riesgo de la exterioridad sin sentir la fascinación de la renuncia.

\section{La fascinación de la renuncia}

En El espacio literario Blanchot plantea que cada uno de los ensayos que lo componen conduce hacia un centro en el cual se encuentra Orfeo, quien para completar su obra debe abandonarla a la suerte misma de la música infernal que ha tenido el privilegio, y al mismo tiempo la desgracia, de escuchar. Es este un claro ejemplo del carácter intempestivo de lo que ocurre en el límite del lenguaje o en el afuera de éste, donde lo único que puede hablar es la renuncia o, mejor dicho, la condena que absuelve a Eurídice y a la obra misma. Tomando por caso este procedimiento alegórico, Blanchot señala la suerte seguida por el escritor en el afuera del lenguaje, en ese espacio que la obra ha sabido habilitar para $s^{17}$.

La renuncia a continuar escribiendo es, por cierto, el triunfo de la fascinación; es el momento en el cual, por ejemplo, "Rimbaud huye al desierto, escapando de las responsabilidades de la decisión poética" y en una transformación sin precedentes "entierra su imaginación y su gloria"; dice "adiós" a "lo imposible" 18 de su deseo. Incapacitado ya para cualquier cosa, hasta para oír hablar de sí mismo, éste "no vuelve al mundo" sino que más bien "se refugia en él, y poco a poco sus días consagrados a la aridez del oro extienden por sobre su cabeza la protección del olvido" ${ }^{19}$.

Como texto crítico El espacio literario no hace otra cosa más que desplegar figuras con las cuales narrar la conflictiva relación entre experiencia y escritura. Ahora bien, como texto de un alto poder metafórico en su intento por pensar dicha relación, el mismo texto puede ser visto como una pormenorizada descripción de ese procedimiento que interesa a la escritura moderna. En la descripción de la experiencia de la obra está contada la experiencia del afuera en el lenguaje; y esa experiencia es el vínculo más estrecho que el artista puede tener con el mundo en el cual su obra se vuelve segunda naturaleza. Fascinados por el límite al
17. Foucault señala que una experiencia de la literatura en Blanchot sería "un tránsito al afuera" un proceso en el cual "el lenguaje escapa al modo de ser del discurso, a la dinastía de la representación"; proceso en donde "la palabra literaria se desarrolla a partir de sí misma". FOUCAULT, Michel. El pensamiento del afuera, 2004, p. 12.

18. BLANCHOT, Maurice. El espacio literario, 1969, p. 45.

19. Ibídem, p. 47. 
20. Ibídem, p. 48.

21. Ibídem, p. 49.

22. George Bataille, gran lector de Kafka y gran lector de Blanchot, define la experiencia interior como un borramiento de lo humano en virtud de experiencias límites como el erotismo, la poesía, el llanto, los raptos que aún nos unen a la animalidad sagrada que es también el comienzo del arte como ritual. Ver entonces BATAILLE, George. La experiencia interior, 2002; El culpable, 1981 y, en particular, el ensayo dedicado a Kafka en La literatura y el mal, 1959. cual ha llegado, Rimbaud, Mallarmé, el mismo Blanchot, una y otra vez sólo pueden contar la paradoja de que ni bien comenzando a elevarse por encima de la vida en la realización de la obra, inmediatamente pierden todo control sobre la ley secreta que hay en ésta. Contrariamente el arte ya no tiene nada que decir cuando ha intentado decirlo todo; en todo caso lo único que le queda por contar es una poderosa necesidad interior de morir contento, de tener que morir para poder escribir, o de tener que escribir para poder morir.

En la intemperie del afuera, en el descenso infernal que iniciara Orfeo y que cada nuevo escritor repite al ir a buscar la singularidad de una experiencia personal, sólo los "creadores viriles", que se acercan al centro del circulo de la obra -sin pretensiones de verdad, o de logros brillantes, y que al salir afuera de ella logran dar por terminada su experiencia, abandonando en ella esa parte de sí de la que todo artista quiere liberarse y que sólo la obra logra liberar- vuelven con "paso calmo hacia la superficie que el trazado regular y firme del radio permite luego redondear según las perfecciones de la esfera" ${ }^{20}$. Transformada en un objeto circular, la obra, el libro, expulsa a su autor, el poema, prescinde de su poeta. Así el círculo de la autonomía del arte se cierra y la subjetividad de quien la llevara adelante accede a "el lugar vacío donde se anuncia la afirmación impersonal" 21.

\section{Kafka y la imposibilidad de continuar la obra}

En Blanchot, la afirmación impersonal a la que todo escritor arriba es un atributo de la obra como proceso; pero también como experiencia límite, como intemperie del ser. En Kafka, como en ningún otro escritor, Blanchot ha visto ese proceso. Cuando el autor de La metamorfosis comprueba en su aspiración de elevar la propia vida a través del arte que en realidad ese deseo es tan inaccesible como el castillo de sus fábulas o el proceso iniciado a sus personajes, en realidad está descubriendo la inmanencia de todo proyecto creativo que no tiene ni comienzo ni fin, que se origina antes del sujeto y que no permite volver a ese origen de todo primer impulso. En definitiva, la impersonalidad que supone la experiencia de la obra es lo que podríamos denominar una experiencia interior tan plena y violenta al mismo tiempo que en ella el sujeto se trasciende a sí mismo ${ }^{22}$.

Siguiendo las anotaciones en el diario del escritor de Praga, Blanchot traza un mapa de los diversos movimientos que llevan a éste a la experiencia de escribir o a la necesidad interior 
que, por momentos, parecen una misma cosa. El primer paso es entregarse a la soledad esencial; y para ello Kafka debe borrar la presencia de su familia, su profesión, los horarios y las obligaciones en todo aquello que marca o delata una pertenencia al mundo ${ }^{23}$. Ocurre que si la escritura es interminable, infinita e imposible de detener al seguir su ley secreta hacia lo impersonal, todo aquello que está fijo e inmóvil alrededor del artista significa un impedimento al continuum del ritmo de la obra. La oposición de Kafka más que a las instituciones que suponen el matrimonio, la familia o la burocracia, es a lo que en éstas hay de negativo para la escritura: su demanda de atención. Por ejemplo, en tanto que proyectos: sus noviazgos, sus ideas sionistas y antisionistas, la cura de su enfermedad, el retorno a la raíz hebraica lo que tienen de terrible es simplemente la demanda de tiempo; tiempo que Kafka no está del todo dispuesto a dar, porque el tiempo ahora es el tiempo de la obra, pues el tiempo, que se debe suspender por medio de una borradura del mundo inmediato, es lo que le otorga a la obra constancia en la duración que demanda su realización. Pero aún así es un tiempo sin comienzo ni final; se trata de un tiempo del orden de la intensidad antes que del orden de la duración. Cuando Kafka duda en otorgar ese requerimiento absoluto, cuando en medio del desierto de la vida cree encontrar un consuelo en la postración o en el cultivo de la tierra y el trabajo manual que detalla en sus últimas anotaciones del Diario, esos nuevos espejismos reflejan una luz oscura en su obra. Es decir, reimprimen las preocupaciones de la realidad y terminan por restar densidad e intensidad no sólo a algunos de sus relatos sino también a la exigencia de la obra, que se pierde en la falta de constancia y en la proliferación del fragmento, lo inconcluso, aquello que la muerte termina por sorprender.

"La felicidad de escribir unas pocas páginas" ${ }^{24}$ es señalada por Kafka en su Diario como su propia salvación y al mismo tiempo como la posibilidad cierta e incierta del quehacer de todo escritor contemporáneo. $\mathrm{Y}$ haciéndose eco de estas palabras, Blanchot sintetiza la frustración de Kafka al observar que para efectuar la obra como tal "necesitaría más tiempo, pero también necesitaría menos mundo" 25 . La felicidad de la escritura que ésta pone al alcance del sujeto que se predispone a realizarla, se resuelve en medio de una paradoja: trascender al mundo dando cuenta de aquello que hace imposible al mundo. Por lo tanto, la obra como exigencia puede ser un artefacto de autonomía plena, puede brindarse como realización estética; pero también puede resolverse en una exigencia de salvación, en el espacio donde el sujeto se disuelve como tal en medio de una soledad esencial donde "escribir no es un llamado, la espera de la gracia o un oscuro cumplimiento profético, sino algo más simple, más inmediatamente apremiante, la esperanza de no hundirse,
23. Un análisis sobre esta relación entre la familia como principio de realidad y el deseo de escritura como elevación hacia lo verdadero, puede observarse en el libro del ensayista argentino Carlos Correas titulado Kafka y su padre, en donde éste sugiere que por medio de la idea de autosacrificio estético "Kafka se repliega frente al mundo dado y este desasimiento es ya liberación; pero además el momento positivo de esta libertad es la transfiguración del mundo en su realidad propia (en su verdad, pureza e inmutabilidad) y la donación de un mundo así al lector"; al mismo tiempo, y en coincidencia con Blanchot, Correas señala ese vinculo entre experiencia de la obra y subjetividad como una afirmación en la cual "trabajar la obra es trabajarse mediante la obra". CORREAS, Carlos. Kafka y su padre, 2004, p. 68-69, 74

24. KAFKA, Franz. Diario 19101923, 1954, p. 125.

25. BLANCHOT, Maurice. El espacio literario, 1969, p. 53. 
26. Ibídem, p. 56 - 57.

27. Ibídem, p. 58.

28. Ibídem, p. 59.

29. Ídem. "Kafka y Brod", 2002b, p. 287.

30. Ídem. "La última palabra", 2002c, p. 306. o, más exactamente, de hundirse más rápido en sí mismo y así rescatarse en el último momento" 26 .

Sin embargo cuando se evalúa lo escrito, o cuando se ve a dónde ha llegado el movimiento de la obra, de qué modo se ha realizado en uno su exigencia, Kafka arriba a cierta decepción inquietante que lo acompañará por el resto de sus días y que Blanchot entiende de un modo proporcional: "Cuanto más escribe, Kafka está menos seguro de escribir”27. La variación registrada en las notas del diario es un claro ejemplo de ese momento indeterminado, frente al cual todo artista entrevé sus límites por lo que Blanchot señala como un desplazamiento de la obra por la vida interior:

El deseo de representar mi fantástica vida interior ha desplazado todo lo demás; y, además, la ha agotado terriblemente y sigue agitándola. Pero mi capacidad de llevar a cabo esa representación no es de ningún modo previsible, tal vez ya se ha consumido para siempre, tal vez retorne, aunque las circunstancias exteriores de mi vida no favorecen ese retorno. ${ }^{28}$

De este modo, en Kafka las transformaciones de la obra son transformaciones de la subjetividad; a medida que ésta avanza algo también lo hace en la percepción inmediata del sujeto, en su mediación escrita, en lo que podríamos llamar el diario de la imposibilidad de continuar la obra. Así, esa transformación va de los relatos al diario y de ahí a la correspondencia, llamando desde ya la atención de Blanchot que se pregunta “¿por qué el que, en la obra, pasa de la objetividad de los relatos a la intimidad del Diario, desciende aún a una noche más sombría donde se dejan oír los gritos de un hombre perdido?"29.

En esos diversos registros de un hombre perdido se narra cómo el escritor expuesto a los requerimientos de la obra, a la demanda de una literatura impersonal y una concentración desmedida, abandona su estancia en la tierra sintiéndose desposeído del mundo y de sí mismo aún cuando la muerte le entregaría la soberanía de la obra:

El escritor tiene miedo a morir porque no ha vivido aún, y no sólo porque le ha faltado la dicha de vivir con una mujer, niños, fortuna; sino porque en lugar de entrar en casa, ha de contentarse con admirarla desde fuera y coronar su techumbre, excluido del disfrute de las cosas por la contemplación que no es posesión. ${ }^{30}$

Así, de momento, la obra es de algún modo -en las consideraciones finales de Kafka tenidas muy en cuenta por Blanchot- una especie de rotunda negación de la escritura que aparece cuando el escritor ya se encuentra inmovilizado y dispuesto a entender el desoído aviso del límite: 
Hay afirmaciones claras: escribir es ponerse fuera de la vida, es gozar con su propia muerte por una impostura que se convertirá en la espantosa realidad; el pobre yo real al que se ofrece la perspectiva de un pequeño viaje está literalmente molido a golpes, atormentado y hecho polvo por el diablo; en adelante, el mundo está prohibido, la vida es imposible, la soledad, inevitable. ${ }^{31}$

\section{La soledad de la escritura}

La literatura es imposible como experiencia pues desde un primer momento es soledad hacia la cual se va, es esa especie de producción decreciente: a mayor intensidad de escritura menor volumen de lo escrito; a mayor deseo de obra menor presencia del mundo, a mayor fascinación por lo representado menor visibilidad de lo escrito ${ }^{32}$. Blanchot mismo lo entiende así al situar en el centro de su libro a Orfeo, quien se encuentra solo por cumplimiento de su tarea como músico, quien se consuela de esa misma soledad con el ejercicio de su arte que lo ha arrojado a la perdida de Eurídice, o quien no tiene ya más nada que decir pues si habla se refiere a algo que está por fuera de lo terrenal. Sin embargo, en los análisis de Kafka que Blanchot continua aquí y allá respondiendo a la soledad esencial que hace a la escritura de la obra, plantea la siguiente pregunta: ¿qué más puede hacer Kafka en la soledad esencial a la cual arriba por medio de la escritura más que seguir escribiendo?, o, en todo caso, ¿qué otra cosa depara la obra como realización más que la imposibilidad de seguir escribiendo?

De este modo en la obra literaria, escritura e imposibilidad, experiencia y negatividad terminan vinculándose en un punto de relación sinonímica: son registro de una experiencia de lo moderno: el afuera de toda representación. En realidad escribir es plantear desde la primera palabra el problema de un límite inexorable; pues antes que reducir la escritura a una explicación conflictiva de su relación con la vida, es preferible hacer de ella el sustento inesperado de una experiencia que jamás se reduce, ya que, vida y obra, recíprocamente, se vinculan: "Escribir, vivir: ¿cómo podría uno atenerse a este enfrentamiento de términos precisamente tan mal determinados? Escribir destruye la vida, preserva la vida, exige la vida, ignora la vida, y recíprocamen-

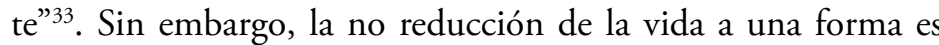
lo que hace de la escritura algo imposible, una serie sucesiva de negaciones que no hacen más que aseverar la imposibilidad de cualquier experiencia. Del mismo modo que los personajes de Kafka no pueden acceder al castillo o al origen del proceso
31. Ibídem, p. 308.

32. En relación a la idea de soledad esencial en la escritura ver el artículo de ARRANZ, Manuel. "De Blanchot a Blanchot: la soledad esencial del escritor", Revista de Occidente, 2003, p. 84-92.

33. BLANCHOT, Maurice. "La palabra completamente última", 2002d, p. 323. 
34. Ibídem, p. 333.

35. Ídem. El espacio literario, 1969, p. 68. que se les inicia, el escritor no puede acceder a una voluntad de juicio en la obra pues la escritura es incierta y perversa. Aquí Blanchot señala claramente que la construcción de un espacio para la escritura es en realidad un descubrimiento paulatino de su poder; el mismo Kafka cree salvarse a través de ella y su exigencia casi monacal, cuando ni bien avizora que

le será preciso renunciar a la esperanza que parecía contener esa exigencia: no sólo la escritura es esencialmente incierta, sino que escribir no es ya mantenerse intacto en la pureza del círculo cerrado, es atraer a lo alto las potencias oscuras, entregarse a su extrańeza perversa y quizá unirse a lo que destruye. ${ }^{34}$

La obra escrita en el límite de lo tolerable, como es el caso de Kafka, otorga "la conciencia de la desgracia"35; transforma la posibilidad de infinito que la obra tiene en la pesadilla de lo indefinido que hay en la vida. Para Blanchot entonces la obra no tiene trascendencia alguna, sino más bien conciencia de la falta de experiencia en una experiencia que de por sí resulta imposible de compartir con el mundo. ¿Qué puede decir aquel que siente la atracción de la fascinación que termina siendo temor? ¿Qué puede contar quien entabla un vínculo diabólico con la escritura para justamente disolver aquello que aparenta una transparencia segura y confortable? La falta de dioses, el exilio y la ausencia de todo pensamiento comunitario o todo impulso hacia ello, terminan antepuestos al deseo de lo imposible en la obra como forma de llevarla adelante. De ahora en más imposible es el deseo de la literatura sin negar lo literario mismo, es decir, sin pensar la literatura como negatividad.

La soledad de Kafka, entonces, resulta ejemplar para la comprensión de la obra pues expone en sí misma una paradoja: su premeditado uso de la escritura en virtud de un fin -salvarsey su imposición de una exigencia para con su actividad literaria -salir del mundo. Lo ascético de la escritura -no escribir para que su realización sea literaria- debe dejar de lado lo humano que aún existe en el sujeto; en el caso de Kafka lo que debe disolverse es el hombre de las preocupaciones talmúdicas, el escritor que quiere volver a la patria o que simplemente escribe atendiendo a la seducción de aquello que lo rodea; pues de lo contrario, la obra jamás será algo más allá de la interioridad. Por lo tanto, la pregunta es ¿cómo continuar la obra si ella pone en peligro lo humano? Si la literatura, esa salvación que Kafka cree emprender como un trabajo que lo devuelve a los hombres, está agotada -disuelta, pronta a dar cuenta de su fin- es justamente porque para la cultura, que se inicia en el renacimiento y llega hasta el romanticismo, hay una imperiosa necesidad de trascendencia en ella. Sin embargo, en busca de esa trascendencia se terminará negando toda posibilidad de darle continuidad a la literatura que así se ve encerrada en 
su mutismo; ¿qué queda en Kafka -quien deseaba elevar la vida a lo puro, lo verdadero, lo imperecedero- más que un deseo de incinerar esos papeles que por tanto tiempo lo distrajeron de la vida y terminaron por agotarla?

\section{La pregunta por la experiencia}

Qué es la experiencia, parecería preguntarse Blanchot a cada paso del itinerario de lectura que realiza Kafka y la salvación, Mallarmé y el pensamiento en movimiento, Rilke y la posibilidad de la experiencia de la muerte- para decretar la imposibilidad de la literatura. Y más allá de eso, lo que sorprende es que este término aparezca - por voluntad del propio Blanchotsuperpuesto a esta necesidad de la obra, confundiéndose cada dos por tres con las definiciones inherentes a ella. Para concluir podríamos decir que cuando Blanchot habla de una experiencia de la obra se está refiriendo a esa imposibilidad de la literatura que se ha vuelto producción decreciente frente a lo ilimitado que irrumpe en la continuidad del mundo, aquello que ha quedado sin palabras o, más aún, aquello que ha quedado por afuera de nuestras palabras. Así, obra y experiencia llaman por momentos a situar el pensamiento en el terreno incierto del "contacto con el ser”. Por lo que podríamos decir que en el círculo de la obra, la experiencia es todo momento de imposibilidad que adquiere conciencia de sí, una vez que en dicho círculo se transforma en potencia, deseo imposible de inicio, acción infinita de escribir. Blanchot constantemente afirma que la obra no se reduce a una cualidad técnica, a una virtud del manejo y la composición; sino que todo lo contrario, es necesariamente un instante excepcional -la experiencia de la obra- en el cual, ante la imposibilidad de que simplemente es "la posibilidad se vuelve poder, en que el espíritu, ley y forma vacía, rica sólo de indeterminación, se convierte en la certeza de una forma realizada"36.

Como podemos apreciar, entonces, en la literatura el deseo de la obra, la experiencia, aparece como un pasaje de la indeterminación -su condición de sensación, recuerdo, pánico- a la determinación -la pregunta por la obra misma en tanto que autonomía-; pero sin confundir este pasaje con la imposición de un limite sino dándole a la experiencia todas las ventajas de la potencia concentrada. Ocurre que para Blanchot el espíritu vacío del formalismo en Valéry por ejemplo, no sirve o no ayuda a mantener lo que, aún bajo la forma, hay de ilimitado en la experiencia; y es esto justamente lo que impulsa esa ambición que otorga un toque de distinción al escritor que emprende una tarea de nunca acabar. 
En una cita de Rilke - "los versos no son sentimientos sino experiencias"- Blanchot aclara que toda experiencia debe ser en algún punto olvidada, sometida al desierto de la necesidad que es el punto de arranque de la obra, ya que sólo así retornará bajo la forma del verso, el cual resuelve su indeterminación sin suspender esa condición que es propia del ser -lo infinito- en el espacio de la escritura. Pero más allá de eso, todos compartimos el terreno de la experiencia y -hasta a los escritores más versados en el manejo compositivo les ocurre- no alcanzamos a percibir la riqueza que hay en ella, la condición que la hace necesaria e interior; no alcanzamos a percibir ese valor inmaterial que la separa de la continuidad cuando se está dispuesto a admitir que Yo es Otro. Blanchot está forzando entonces una vez más la pregunta del origen como acontecimiento absoluto de la literatura, la cual transforma una serie de sucesos continuos en la fascinación que impulsa la discontinuidad de la obra. Así en tanto que la literatura es interrogación, también es búsqueda de la suspensión de ese origen; y a la pregunta por qué escribir, por qué entregarse a la experiencia de una búsqueda esencial pero imposible, Blanchot simplemente responde porque "hay que agotar la vida para escribir un solo verso"37; y en ese agotamiento, reside la obtención de la búsqueda como afirmación vital, como experiencia que sobresale porque simplemente es, pero ya no puede reiterarse. 


\section{Referencias}

AGAMBEN, Giorgio. Infancia e historia. Destrucción de la experiencia y origen de la historia. Buenos Aires: Adriana Hidalgo, 1969.

El lenguaje y la muerte, Un seminario sobre el lugar de la negatividad. Valencia: Pre-textos, 2008.

AIRA, César. "La nueva escritura". Revista Boletín. n. 8, p. 165170, 2000.

ARRANZ, Manuel. "Blanchot, la literatura y la muerte". In: . Los intelectuales en cuestión. Madrid: Tecnos, 2003, p.

174-183.

. "De Blanchot a Blanchot: la soledad esencial del escritor". Revista de Occidente. n. 265, p. 127-137, 2003.

AYACHE, Élie. L'écriture Postérieure. Paris: Complicités, 2006.

BATAILLE, George. La literatura y el mal. Madrid: Taurus, 1959.

El culpable. Madrid: Taurus, 1981.

2002.

. La experiencia interior. Madrid: Editora Nacional,

BIDENT, Christophe. Maurice Blanchot, partenaire invisible.

París: Éditions Champ Vallon, 1998.

BLANCHOT, Marice. El espacio literario. Buenos Aires: Siglo XXI, 1969.

"Los grandes reductores". In: . La amistad.

Madrid: Editora Nacional, 2002a.

"Kafka y Brod". In: La amistad. Madrid:

Editora Nacional, 2002b.

"La última palabra". In: La amistad. Madrid:

Editora Nacional, 2002c.

"La palabra completamente última". In: . $L a$

amistad. Madrid: Editora Nacional, 2002d.

BÜRGER, Christa; BÜRGER, Peter. La desaparición del sujeto. Una historia de la subjetividad de Montaigne a Blanchot. Madrid: Akal, 2001.

COLLIN, Françoise. Maurice Blanchot et la question de l'écriture. Paris: Gallimard, 1971. 
CORREAS, Carlos. Kafka y su padre. Buenos Aires: Leviatán, 2004.

CUETO, Sergio. Maurice Blanchot. El ejercicio de la paciencia. Rosario: Beatriz Viterbo Editora, 1997.

DANTO, Arthur. Después del fin del arte, Barcelona: Paidós, 1999.

DEL BARCO, Oscar. La intemperie sin fin. Córdoba: Alción Editora, 2008.

FOUCAULT, Michel. El pensamiento del afuera. Valencia: Pretextos, 2004.

HILL, Leslie. Blanchot: Extreme Contemporary. Londres: Routledge, 1997.

KAFKA, Franz. Diario 1910-1923. Buenos Aires: Emecé, 1954.

LIMET, Yun Sun. Maurice Blanchot critique. París: Éditions de la Différence, 2010.

MICHAUD, Ginette. Tenir au secret (Derrida, Blanchot). París: Galilée, 2006.

RANCIÈRE, Jacques. La palabra muda. Ensayos sobre las contradicciones de la literatura. Buenos Aires: Eterna Cadencia, 2009.

SAMANIEGO, Alberto Ruiz. "Maurice Blanchot: una estética de lo neutro". Revista Anthropos: Huellas del conocimiento. n. 192-193, p. 103-112, 2001.

SCHULTE NORHOLT, Anne-Lise. Maurice Blanchot.

L'écriture comme expérience du dehors. Ginebra: Droz, 1995.

ZARADER, Marlène. L'être et le neutre. À partir de Maurice Blanchot. París: Verdier editions, 2002. 